\title{
Experimental Study of Dynamic Bending Stiffness of ACSR Overhead Conductors
}

\author{
Frédéric Lévesque, Sylvain Goudreau, Sébastien Langlois, and Frédéric Légeron
}

\begin{abstract}
Aeolian vibrations of transmission line conductors may cause fretting fatigue failure at or near the location of clamped devices. At these locations, the bending stiffness variation of the conductor has a large influence on its deformed shape and hence on its fatigue mechanics. Variable bending stiffness models could be integrated in non-linear finite element programs to obtain better mechanical behaviour predictions. However, there is very little data available in the literature to validate such numerical models. The objective of this paper is to present experimental data for the deformed shape of two types of ACSR conductors undergoing vibrations. The tests were performed on a $5.83 \mathrm{~m}$ test bench for various tensions, displacement amplitudes and frequencies. The displacement amplitude was measured at the vibration anti-node and at five locations near the squarefaced bushing. The results suggest a large stiffness variation near the bushing. This experimental study provides valuable data to compare with a numerical model of a vibrating conductor that includes variable bending stiffness.
\end{abstract}

\section{INTRODUCTION}

A EOLIAN vibrations of transmission line conductors are caused by vortex shedding in the wake of the conductor occurring in light steady wind conditions. This type of vibrations may cause fretting fatigue failure at or near the location of clamped devices. At these locations, the bending stiffness variation of the conductor has a large influence on its deformed shape and hence on its fatigue mechanics.

The bending stiffness of cables varies with curvature [1] and many models to describe the non-linear variation of bending stiffness of conductors have been proposed [2]-[4]. This type of models can be implemented in the finite element programs as shown by Dastous [5] and Langlois et al. [6]. The models are based on the fact that as curvature increases, some wires will slip, hence decreasing the global bending stiffness of the whole cable. To validate his analytical model, Papailiou [2] has performed a static test on a short cable test bench. To further verify the bending stiffness models, and define how it can be applied for the prediction of the deformed shape of conductors during aeolian vibrations, one would need to implement it in a finite element program and compare it to experimental data for a vibrating conductor. However, very few papers present such

F. Lévesque is with RD Énergie, Québec, Canada.

S. Goudreau was with the Mechanical Engineering Department at Université Laval, Québec, Canada and he is now retired.

S. Langlois is with the Civil Engineering Department at Université de Sherbrooke, Québec, Canada.

F. Légeron is with Parsons Corporation, UAE.

Manuscript received xx. This work was supported by Hydro-Québec TransÉnergie (HQT), RTE, Helix Uniformed, and the National Sciences and Engineering Research Council of Canada (NSERC) through the Chair HQ/RTE on Mechanics and Structures of Overhead Transmission Lines. data [7], [8], and none is detailed enough to assess adequately the performance of bending stiffness models.

The objective of this paper is to present experimental data for the deformed shape of two ACSR conductors undergoing small amplitude vibrations. The tests were performed on a $5.83 \mathrm{~m}$ test bench with three levels of tensions, six levels of displacement amplitudes, and three excitation frequencies. The displacement amplitude was measured at the vibration antinode and at four locations near the clamp, where displacement amplitude is affected by the varying bending stiffness.

Section II presents the experimental program and the test set-up. In Section III, the results for the deformed shape for the various test parameters are first presented. Then, the variability between similar specimens, the effect of the clamping torque, and the effect of static tension are studied. Next, a method to evaluate an equivalent, constant bending stiffness is shown and the results are analyzed. The localization of fretting marks are presented, these marks being symptomatic of wires sliding on each other. Finally, in Section IV, a simple model with two distinct values of bending stiffness is used to compute an order of magnitude of the bending stiffness near the anchor bushing.

\section{EXPERIMENTAL PROGRAM}

A resonance fatigue test bench of the GREMCA laboratory (Université Laval, Québec, Canada) was used to measure the deformed shape of ACSR (Aluminium Conductor Steel Reinforced) conductors. The test bench was previously described in [9] and [10]. Four conductor specimens were tested: three Drake and one Bersfort, whose geometrical and mechanical properties are presented in Table I. An ACSR Crow was also tested and showed similar results. To avoid the complex end effect of commercial clamps, a square-faced bushing was used (see Fig. 1). Conductors were clamped with a 47.5 $\mathrm{Nm}(35 \mathrm{lb} \cdot \mathrm{ft}$ ) torque unless otherwise specified. At the end opposite from the instrumented bushing, an electromagnetic shaker was placed at $0.33 \mathrm{~m}$ from the anchoring metal squarefaced bushing; this shaker excited the $5.83 \mathrm{~m}$ active length of conductors at one of their resonance frequencies. The link between the shaker and the conductor was monitored with a load cell and an accelerometer. The control parameters were the frequency and the peak-to-peak bending amplitude $Y_{b}$ measured at $89 \mathrm{~mm}$ from the last point of contact (LPC) between the conductor and the instrumented bushing. Another frequently used vibration parameter is the frequency multiplying the anti-node amplitude $f y_{\max }$. It was thus computed afterwards.

Bending amplitudes $Y_{b}$ ranged from 0.10 to $0.60 \mathrm{~mm}$ by increments of $0.10 \mathrm{~mm}$. Peak-to-peak vibration amplitudes 


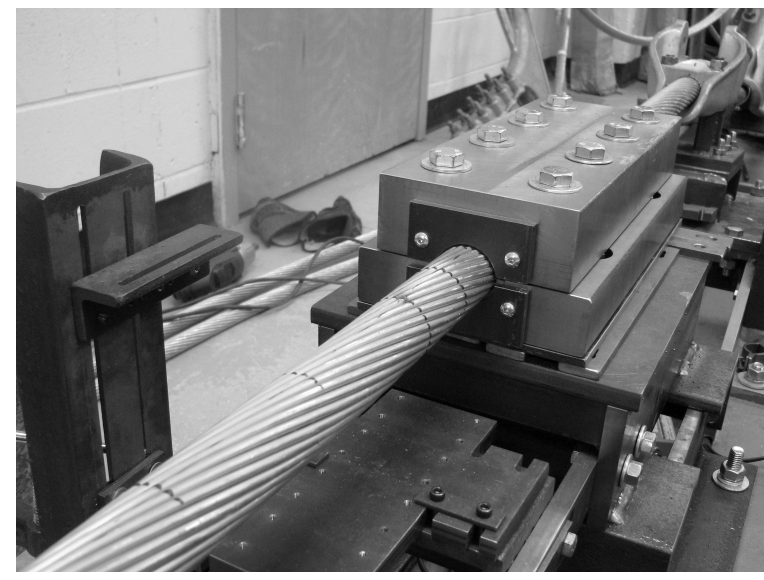

Fig. 1. Rigid square-faced bushing on the cable test bench.

TABLE I

MECHANICAL PROPERTIES OF THE CONDUCTORS

\begin{tabular}{|l|c|c|}
\hline ACSR Conductor & Drake & Bersfort \\
\hline Total area $\left(\mathrm{mm}^{2}\right)$ & 468.0 & 748.0 \\
\hline Conductor diameter $(\mathrm{mm})$ & 28.14 & 35.6 \\
\hline Number of wires on each layer & & \\
\hline - Steel & $1-6$ & $1-6$ \\
\hline - Aluminium & $10-16$ & $10-16-22$ \\
\hline Lay angle ${ }^{\circ}$ ) & & \\
\hline - Steel layer 2 & 5.8 & 6.2 \\
\hline - Aluminium layer 3 & - & 9.7 \\
\hline - Aluminium layer 2 & 10.7 & 10.7 \\
\hline - Aluminium layer 1 (outer) & 12.9 & 11.7 \\
\hline Diameter of steel wires $(\mathrm{mm})$ & 3.45 & 3.32 \\
\hline Diameter of aluminium wires $(\mathrm{mm})$ & 4.44 & 4.27 \\
\hline Linear mass (kg/m) & 1.628 & 2.370 \\
\hline Aluminium modulus of elasticity $(\mathrm{GPa})$ & 68.9 & 68.9 \\
\hline Steel modulus of elasticity $(\mathrm{GPa})$ & 207 & 207 \\
\hline Minimum bending stiffness $\left(\mathrm{Nm}^{2}\right)$ & 43.4 & 61.6 \\
\hline Maximum bending stiffness $\left(\mathrm{Nm}^{2}\right)$ & 1495 & 3827 \\
\hline Rated tensile strength $(\mathrm{kN})$ & 140.1 & 180.1 \\
\hline
\end{tabular}

were measured at $44.45 \mathrm{~mm}\left(Y_{45}\right), 88.9 \mathrm{~mm}\left(Y_{b}\right), 133.35$ $\mathrm{mm}\left(Y_{134}\right), 177.8 \mathrm{~mm}\left(Y_{178}\right)$, and $266.7 \mathrm{~mm}\left(Y_{267}\right)$, except in the cases of the Drake-2 and Drake-3 specimens where $Y_{134}$ was not recorded. The anti-node amplitude $y_{\max }$ was also monitored at the center loop for odd modes or at the loop near the middle of the test length for even modes in order to minimize the influence of end conditions. Three vibration modes (3rd, 4th and 5th) were imposed at each of the three levels of static tensions $(15 \%, 25 \%$ and $35 \%$ of Rated Tensile Strength (RTS)). This makes 54 test conditions for every conductor specimen, except for the Drake-3. The purpose of this last specimen was to assess the effect of the clamping torque used for tightening the fastening bolts of the squarefaced bushing. Rather than changing the static tension, which was kept at $25 \%$ RTS, the clamping torque was increased from $27.1 \mathrm{Nm}(20 \mathrm{lb} \cdot \mathrm{ft})$ to $47.5 \mathrm{Nm}(35 \mathrm{lb} \cdot \mathrm{ft})$ and finally $67.8 \mathrm{Nm}$ $(50 \mathrm{lb} \cdot \mathrm{ft})$. Vibration nodes were also localized.

Methodology and partial results were presented in [11] and used to validate the numerical model of a vibrating conductor [6].

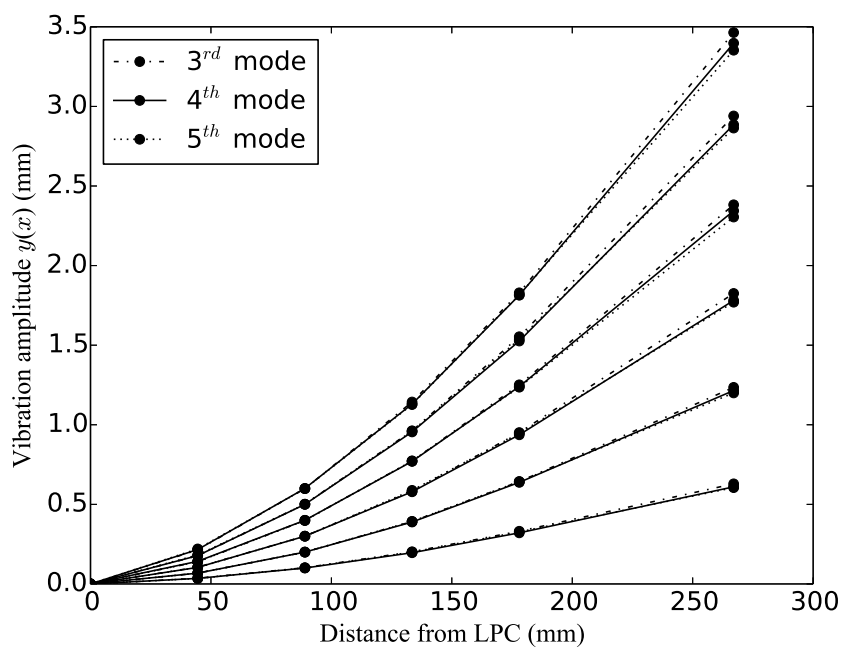

Fig. 2. Deformed shape of ACSR Drake-1 at $15 \%$ RTS.

\section{EXPERIMENTAL RESULTS}

The deformed shape of conductors can be drawn from the collected data (Fig. 2 for example). Near the bushing, amplitudes are not influenced significantly by the mode. The variation is under $3.9 \%$ at $133.35 \mathrm{~mm}$ from the bushing and no particular mode seems to yield larger displacement than others. Of course, the effect of the mode becomes more important away from the bushing. Displacements are larger at a larger wavelength. Tables II and III report recorded data. These tables present the peak-to-peak (pk-pk) displacement amplitudes at four locations, the maximum 0-peak (0-pk) antinode displacement $y_{\max }$, the static tension $H$, the excitation frequency $f$, and the excitation force $F$.

\section{A. Variation of bending stiffness between specimens}

Results from the three Drake specimens were compared to assess the variability of the deformed shape of conductors vibrating at a given $Y_{b}$. Ratios of $Y_{45}$ and $y_{\max }$ were computed.

TABLE II

DRAKE-1 THIRD MODE

\begin{tabular}{|c|c|c|c|c|c|c|c|}
\hline$H$ & $f$ & $F$ & $Y_{45}$ & $Y_{b}$ & $Y_{178}$ & $Y_{267}$ & $y_{\max }$ \\
\hline $\mathrm{kN}$ & $\mathrm{Hz}$ & $\mathrm{N}$ & $\begin{array}{c}\mathrm{mm} \\
\mathrm{pk}-\mathrm{pk}\end{array}$ & $\begin{array}{c}\mathrm{mm} \\
\mathrm{pk}-\mathrm{pk}\end{array}$ & $\begin{array}{c}\mathrm{mm} \\
\mathrm{pk}-\mathrm{pk}\end{array}$ & $\begin{array}{c}\mathrm{mm} \\
\mathrm{pk}-\mathrm{pk}\end{array}$ & $\begin{array}{c}\mathrm{mm} \\
0-\mathrm{pk}\end{array}$ \\
\hline 20.80 & 31.16 & 2.19 & 0.0355 & 0.102 & 0.331 & 0.629 & 1.42 \\
\hline 20.82 & 31.13 & 6.78 & 0.0680 & 0.200 & 0.643 & 1.235 & 2.75 \\
\hline 20.83 & 31.11 & 14.31 & 0.1053 & 0.300 & 0.951 & 1.825 & 3.96 \\
\hline 20.83 & 31.07 & 24.24 & 0.1397 & 0.399 & 1.251 & 2.382 & 5.12 \\
\hline 20.87 & 31.07 & 35.54 & 0.1770 & 0.501 & 1.553 & 2.940 & 6.14 \\
\hline 21.00 & 31.18 & 46.47 & 0.2137 & 0.599 & 1.829 & 3.464 & 7.07 \\
\hline 33.73 & 39.80 & 4.84 & 0.0366 & 0.102 & 0.308 & 0.581 & 1.20 \\
\hline 33.67 & 39.77 & 11.75 & 0.0710 & 0.200 & 0.619 & 1.167 & 2.33 \\
\hline 33.57 & 39.77 & 20.46 & 0.1060 & 0.300 & 0.918 & 1.712 & 3.39 \\
\hline 33.68 & 39.78 & 31.17 & 0.1417 & 0.400 & 1.227 & 2.248 & 4.49 \\
\hline 33.75 & 39.78 & 43.04 & 0.1770 & 0.500 & 1.515 & 2.735 & 5.42 \\
\hline 33.83 & 39.76 & 55.44 & 0.2140 & 0.600 & 1.796 & 3.201 & 6.25 \\
\hline 47.94 & 46.87 & 9.33 & 0.0370 & 0.100 & 0.300 & 0.547 & 1.01 \\
\hline 47.82 & 46.82 & 19.02 & 0.0717 & 0.200 & 0.595 & 1.086 & 2.00 \\
\hline 47.73 & 46.80 & 30.14 & 0.1080 & 0.300 & 0.893 & 1.633 & 3.03 \\
\hline 46.99 & 46.70 & 42.28 & 0.1430 & 0.400 & 1.187 & 2.166 & 4.06 \\
\hline 47.39 & 46.74 & 55.84 & 0.1804 & 0.500 & 1.475 & 2.689 & 5.01 \\
\hline 47.46 & 46.72 & 70.02 & 0.2180 & 0.600 & 1.759 & 3.185 & 5.92 \\
\hline
\end{tabular}


For example, the ratio $Y_{45(D 2)} / Y_{45(D 1)}$ is the displacement measured at $44.45 \mathrm{~mm}$ from the bushing on the second Drake on the displacement measured at the same position on the first Drake. The mean, standard deviations and range of values of the different ratios are reported in Table IV. There are eighteen data points in each data set: six bending amplitudes measured at three different vibration modes.

The mean variation on $Y_{45}$ values is of $5 \%$, with a maximum variation of $9 \%$. The mean variation is of $4 \%$ on values of $y_{\max }$, with a maximum difference of $11 \%$. The largest differences are observed at $Y_{b}=0.10 \mathrm{~mm}$. This is potentially due to the relatively larger errors associated with measurements of small displacements. Otherwise results are rather constant, no matter the bending amplitude $Y_{b}$. No trend was observed depending on mode or static tension.

The variation between specimens is consistent with the one observed among Lévesque's results [12]. For instance, a maximum difference of $7 \%$ was observed on $y_{\max }$ among eleven specimens tested at a same bending amplitude $\left(Y_{b}=\right.$ $0.75 \mathrm{~mm}$ ) on the same test bench.

\section{B. Clamping torque}

Increasing the clamping torque introduces two competing effects. Clamping restrains axial displacements of wires, impeding interwire slip. This preserves a relatively high bending stiffness near the clamp. On the other hand, clamping reduces the diameter of the conductor, hence shortening the helical path of wires (if we suppose a constant lay angle during the clamping process). The extra length reduces strains at the exit of the bushing. This relaxation also decreases contact pressure between wires of adjacent layers, easing slipping and sliding, hence promoting a decreased bending stiffness.

Increasing clamping torque led to smaller measured displacements $Y_{45}$. That suggests that an increased clamping torque stiffens the conductor near the bushing. An increased $y_{\max }$ is also observed because a higher excitation level is

TABLE III

BERSFORT-1 THIRD MODE

\begin{tabular}{|c|c|c|c|c|c|c|c|}
\hline$H$ & $f$ & $F$ & $Y_{45}$ & $Y_{b}$ & $Y_{178}$ & $Y_{267}$ & $y_{\max }$ \\
\hline $\mathrm{kN}$ & $\mathrm{Hz}$ & $\mathrm{N}$ & $\begin{array}{c}\mathrm{mm} \\
\mathrm{pk}-\mathrm{pk}\end{array}$ & $\begin{array}{c}\mathrm{mm} \\
\mathrm{pk}-\mathrm{pk}\end{array}$ & $\begin{array}{c}\mathrm{mm} \\
\mathrm{pk}-\mathrm{pk}\end{array}$ & $\begin{array}{c}\mathrm{mm} \\
\mathrm{pk}-\mathrm{pk}\end{array}$ & $\begin{array}{c}\mathrm{mm} \\
0-\mathrm{pk}\end{array}$ \\
\hline 27.63 & 30.80 & 4.09 & 0.0398 & 0.100 & 0.296 & 0.573 & 1.49 \\
\hline 27.70 & 30.82 & 13.42 & 0.0778 & 0.200 & 0.586 & 1.129 & 2.89 \\
\hline 27.74 & 30.85 & 28.19 & 0.1155 & 0.300 & 0.870 & 1.668 & 4.16 \\
\hline 27.76 & 30.86 & 46.40 & 0.1539 & 0.400 & 1.134 & 2.178 & 5.39 \\
\hline 27.77 & 30.85 & 61.64 & 0.1929 & 0.500 & 1.402 & 2.672 & 6.48 \\
\hline 27.76 & 30.82 & 76.26 & 0.2310 & 0.600 & 1.646 & 3.142 & 7.47 \\
\hline 45.34 & 38.64 & 5.66 & 0.0409 & 0.100 & 0.290 & 0.552 & 1.27 \\
\hline 45.44 & 38.69 & 15.47 & 0.0811 & 0.200 & 0.585 & 1.099 & 2.56 \\
\hline 45.53 & 38.78 & 30.14 & 0.1194 & 0.300 & 0.873 & 1.651 & 3.80 \\
\hline 45.59 & 38.84 & 50.45 & 0.1618 & 0.400 & 1.160 & 2.184 & 5.00 \\
\hline 46.19 & 38.91 & 69.46 & 0.2020 & 0.500 & 1.417 & 2.653 & 6.16 \\
\hline 46.16 & 38.97 & 93.51 & 0.2430 & 0.600 & 1.680 & 3.169 & 7.12 \\
\hline 62.69 & 44.99 & 9.01 & 0.0406 & 0.100 & 0.287 & 0.524 & 1.16 \\
\hline 62.77 & 45.01 & 18.85 & 0.0802 & 0.200 & 0.574 & 1.070 & 2.34 \\
\hline 62.56 & 45.01 & 28.36 & 0.1275 & 0.300 & 0.858 & 1.592 & 3.42 \\
\hline 62.57 & 45.04 & 41.89 & 0.1706 & 0.400 & 1.140 & 2.138 & 4.55 \\
\hline 62.57 & 45.04 & 58.17 & 0.2021 & 0.500 & 1.423 & 2.652 & 5.59 \\
\hline 62.53 & 45.03 & 68.92 & 0.2490 & 0.600 & 1.690 & 3.112 & 6.58 \\
\hline
\end{tabular}


be analytically described by the following equations [13]:

$$
\begin{aligned}
& y(x)=y_{\max }[ \sin (\beta x)-\beta / \alpha[\sinh (\alpha x) \\
&+\tanh (\alpha L)(\cos (\beta x)-\cosh (\alpha x))]] \\
& \alpha=\sqrt{\frac{H}{2 E I}+\sqrt{\frac{m \omega_{n}^{2}}{E I}+\left(\frac{H}{2 E I}\right)^{2}}} \\
& \beta=\sqrt{-\frac{H}{2 E I}+\sqrt{\frac{m \omega_{n}^{2}}{E I}+\left(\frac{H}{2 E I}\right)^{2}}}
\end{aligned}
$$

$L$ is the conductor length, $H$ the static tension, $\omega_{n}$ the circular frequency and EI the bending stiffness. The node shift is clearly seen on Fig. 3 where equation 1 is used to calculate the deformed shape for mode 5 with the frequency calculated according to wavelength measured experimentally. The wavelength is taken as the average of the distance to 3rd, 4th and 5th nodes shown in Table VI for Drake-1 conductor at mode 5. Larger displacements are also visible near the bushing, although it is best seen on Fig. 4. On this last figure, $Y_{b}$ is kept constant at $0.3 \mathrm{~mm}$.

This behavior could have impacts on fatigue performances of conductors, as suggested by kinematic models such as those from Lutchansky [14], Knapp [15] or Feld et al. [16]. Fadel et al. [17] published a $\sigma_{a}\left(Y_{b}\right)-N$ diagram (stress calculated from bending amplitude $Y_{b}$ versus number of cycles) with 35 tests in the 1-25 Mc range for a conductor having being tested at two different tension forces; they concluded that the fatigue life is significantly affected by an increase of the conductor tension. On the other hand, Rawlins [18] published a $\sigma_{a}\left(f y_{\max }\right)-N$ diagram based on a larger number of tests $(63$ tests at different conductor tension, in the 1-500 Mc range) and the drawn conclusion was that the $\sigma_{a}-N$ relationship was not significantly affected by conductor tension [9], [18]. Both stress fatigue indicators $\sigma_{a}\left(Y_{b}\right)$ and $\sigma_{a}\left(f y_{\max }\right)$ are computed taking into account the conductor tension but their relationships to the tension force are different [19]. Finite element studies [20] have shown little influence of static tension on contact stresses. From what it is mentioned above, the fatigue load at the bushing (or clamp) versus the conductor tension shall be further investigated to get a sounder conclusion.

\section{Equivalent bending stiffness}

Eq. 1 can be used to determine the global stiffness a conductor should have to fit experimental results. For a given $y_{\max }$, circular frequency $\omega_{n}$, amplitude $y(x)$, a stiffness $E I$ is found by iteration. An example of obtained results is found in Table VII. In this table, $E I_{p}$ is obtained by dividing $E I$ by $E I_{\max }$. We observe that an important decrease of global stiffness is necessary to fit experimental data as we get near the bushing. As expected, the decrease is more important with an increased $Y_{b}$. This tendency exists at every mode and tension tested. Otherwise, the global stiffness is rather constant around $0.5 E I_{\max }$, a value advocated by CIGRÉ [21]. The decrease in bending stiffness very near the bushing is however not expected to be important since the clamping effect

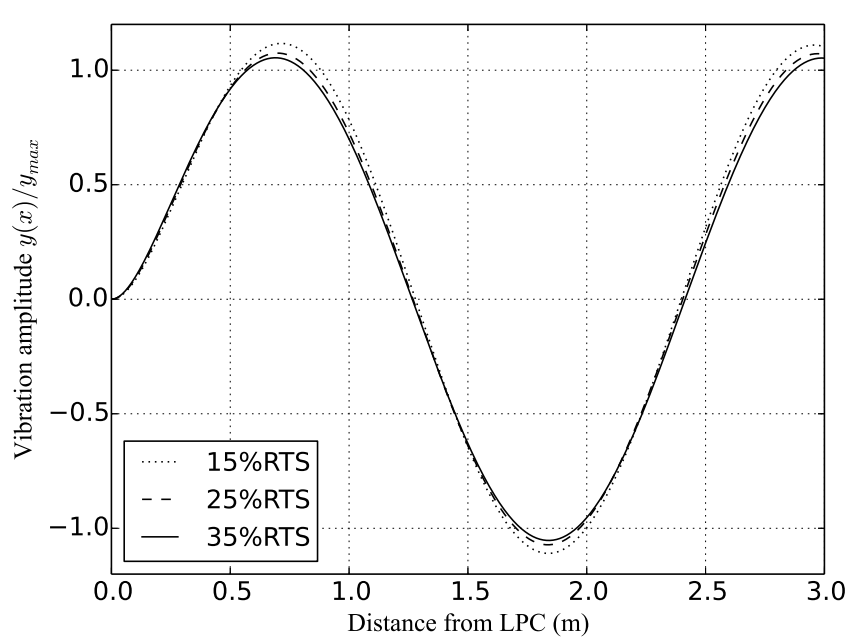

Fig. 3. Deformed shape of ACSR Drake-1 at mode 5.

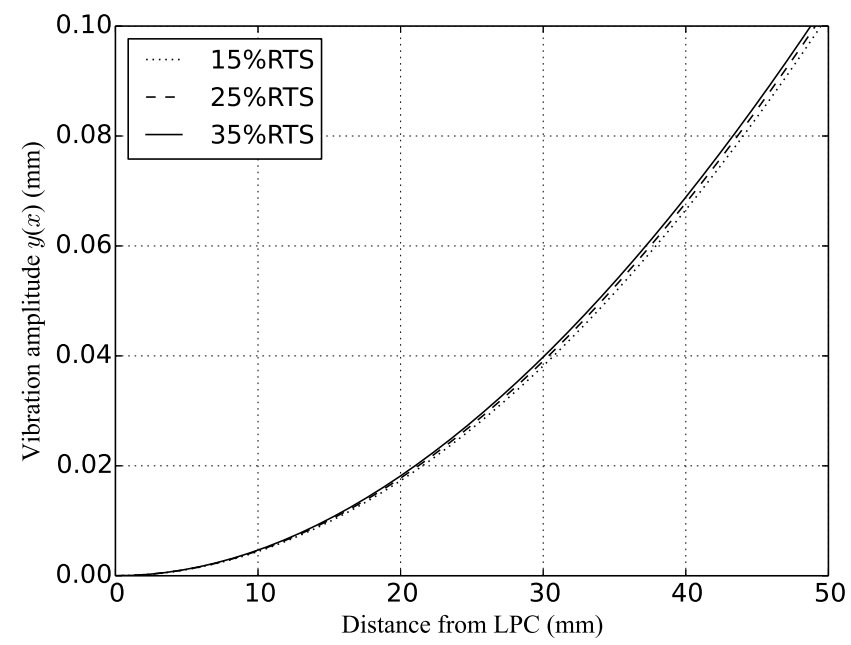

Fig. 4. Deformed shape of ACSR Drake-1 at mode 5.

of the bushing should prevent the sliding of the wires even if the bending curvature is high at the exit of the square-faced bushing. The fact that there is a reduced bending stiffness for all bending amplitudes may mean that the clamp did not provide a perfect fixed boundary condition.

In order to get other convincing facts that the conductor bending stiffness varies much near the ends, the measured deformed shape is compared to the theoretical one given by equation 1. Results for the Drake-1, 15\%RTS, third mode, are compared to a theoretical conductor of constant bending stiffness $E I=0.3 E I_{\max }$ on Fig. 5. That particular stiffness was chosen purely for illustrative purposes since it shows best the tendencies, but these are always observed at any stiffness value. The theoretical constant bending stiffness model underestimates displacements near the bushing and overestimates them as we move toward the center of the span.

\section{E. Localization of fretting marks}

The stiffness decrease being caused by wire slippage, fretting marks along the conductor, and most notably near clamped equipment, are a good indicator of bending stiffness variations. Aluminium fretting generates a distinctive black 
TABLE VI

LOCALIZATIONS OF NODES

\begin{tabular}{|c|c|c|c|c|c|}
\hline \multicolumn{6}{|c|}{ Drake-1 } \\
\hline Mode & \multicolumn{5}{|c|}{ Node } \\
\hline $15 \% \mathrm{RTS}$ & $1 \mathrm{st}(\mathrm{mm})$ & 2nd (mm) & 3rd (mm) & 4th (mm) & 5 th $(\mathrm{mm})$ \\
\hline 5th & 1289 & 1122 & 1115 & 1120 & 1184 \\
\hline 4th & 1560 & 1392 & 1397 & 1481 & \\
\hline $3 \mathrm{rd}$ & 2025 & 1815 & 1990 & & \\
\hline \multicolumn{6}{|l|}{$25 \%$ RTS } \\
\hline 5 th & 1265 & 1136 & 1131 & 1139 & \multirow[t]{3}{*}{1159} \\
\hline 4th & 1544 & 1402 & 1410 & 1474 & \\
\hline $3 \mathrm{rd}$ & 2007 & 1843 & 1980 & & \\
\hline \multicolumn{6}{|l|}{$35 \%$ RTS } \\
\hline 5th & 1254 & 1155 & 1146 & 1145 & \multirow[t]{3}{*}{1130} \\
\hline 4th & 1544 & 1402 & 1421 & 1463 & \\
\hline $3 \mathrm{rd}$ & 2007 & 1843 & 1980 & & \\
\hline \multicolumn{6}{|c|}{ Bersfort-1 } \\
\hline Mode & \multicolumn{5}{|c|}{ Node } \\
\hline $15 \% \mathrm{RTS}$ & 1st (mm) & 2nd (mm) & 3rd (mm) & 4th (mm) & 5 th $(\mathrm{mm})$ \\
\hline 5th & 1282 & 1105 & 1102 & 1111 & 1230 \\
\hline 4th & 1572 & 1364 & 1373 & 1521 & \\
\hline $3 \mathrm{rd}$ & 2028 & 1804 & 1998 & & \\
\hline \multicolumn{6}{|l|}{$25 \% \mathrm{RTS}$} \\
\hline 5th & 1285 & 1111 & 1106 & 1116 & \multirow[t]{3}{*}{1212} \\
\hline 4th & 1558 & 1381 & 1382 & 1509 & \\
\hline $3 \mathrm{rd}$ & 2028 & 1826 & 1976 & & \\
\hline \multicolumn{6}{|l|}{$35 \%$ RTS } \\
\hline 5 th & 1261 & 1123 & 1119 & 1120 & \multirow[t]{3}{*}{1207} \\
\hline 4th & 1547 & 1398 & 1397 & 1488 & \\
\hline $3 \mathrm{rd}$ & 2012 & 1848 & 1970 & & \\
\hline
\end{tabular}

TABLE VII

EQUIVALENT BENDING STIFFNESS - DRAKE-1 15\%RTS

\begin{tabular}{|c|c|c|c|c|c|c|}
\hline $\begin{array}{c}\text { Tension } \\
(\mathrm{kN})\end{array}$ & $\begin{array}{c}\text { Freq. } \\
(\mathrm{Hz})\end{array}$ & $\begin{array}{c}Y_{b} \\
(\mathrm{~mm})\end{array}$ & $\begin{array}{c}E I_{p} \\
45 \mathrm{~mm}\end{array}$ & $\begin{array}{c}E I_{p} \\
89 \mathrm{~mm}\end{array}$ & $\begin{array}{c}E I_{p} \\
178 \mathrm{~mm}\end{array}$ & $\begin{array}{c}E I_{p} \\
267 \mathrm{~mm}\end{array}$ \\
\hline 20.8 & 31.2 & 0.1 & 0.234 & 0.431 & 0.503 & 0.551 \\
\hline 20.8 & 31.1 & 0.2 & 0.240 & 0.415 & 0.496 & 0.520 \\
\hline 20.8 & 31.1 & 0.3 & 0.201 & 0.370 & 0.453 & 0.467 \\
\hline 20.8 & 31.1 & 0.4 & 0.188 & 0.341 & 0.425 & 0.447 \\
\hline 20.9 & 31.1 & 0.5 & 0.164 & 0.300 & 0.378 & 0.397 \\
\hline 21 & 31.2 & 0.6 & 0.147 & 0.273 & 0.353 & 0.364 \\
\hline 20.5 & 55.7 & 0.1 & 0.291 & 0.555 & 0.657 & 0.772 \\
\hline 20.4 & 55.5 & 0.2 & 0.289 & 0.542 & 0.655 & 0.742 \\
\hline 20.4 & 55.1 & 0.3 & 0.250 & 0.475 & 0.603 & 0.664 \\
\hline 20.5 & 54.9 & 0.4 & 0.198 & 0.389 & 0.507 & 0.546 \\
\hline 20 & 53.3 & 0.5 & 0.146 & 0.306 & 0.393 & 0.403 \\
\hline 20.0 & 52.9 & 0.6 & 0.134 & 0.285 & 0.377 & 0.402 \\
\hline
\end{tabular}

powder. On the other hand, no conclusion was drawn from the steel wires. It has been difficult to distinguish fretting marks from wear originating from the manufacturing and handling of the conductor. The steel core contributing much less to the total bending stiffness of the conductor compared to the aluminium wires, that fact does not impact much our analysis. The observed fretting marks are the result of the loading causing the maximum slippage of wires, which is the maximum bending amplitude of $0.60 \mathrm{~mm}$ with a minimum tension (15\%RTS).

We use the term slipping when only a part of the contact area sees relative motion between surfaces (we then observe a slip annulus surrounding a stick area), while we use sliding when there is a bulk relative displacement of the bodies in contact. Slipping is well known to be prone to initiate propagating cracks [22] leading to premature failure. We observe fretting fatigue at these locations. In the second case, that is sliding, wear is rather the dominant damaging process.

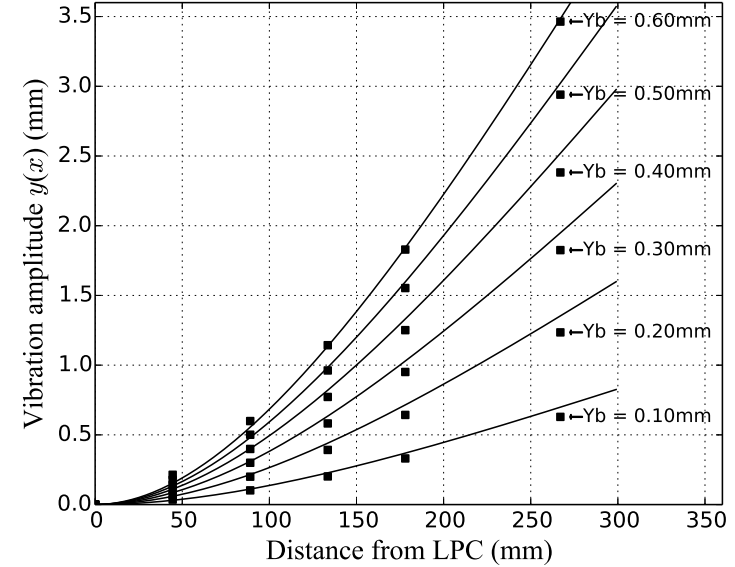

Fig. 5. Experimental data vs the theoretical deformed shape of a constant stiffness conductor $(\mathrm{EI}=0.3 \mathrm{EImax})$ - Drake-1, 15\%RTS, 3rd mode.

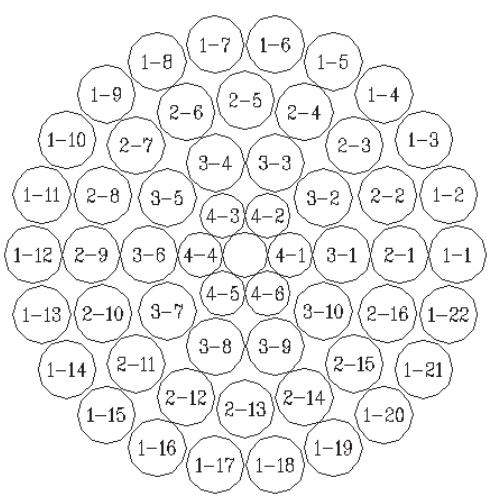

Fig. 6. Section of a ACSR Bersfort at last point of contact, with wire numbering.

This damage is less critical since it wears off cracks as they appear. We observe fretting wear at these locations. Fretting wear generally does not affect much the life of a conductor in service when compared to fretting fatigue.

Fig. 6 shows the numbering of wires at the conductor section at the square-faced bushing end. Fig. 7, 8 and 9 show the location of contact points for the Bersfort conductor, and whether sticking, sliding or slipping was observed. The neutral axis, the top and the bottom of the conductors are also indicated. Data for the Drake are not shown since dirt inside the conductor prevented a reliable observation of interlayer contact points.

Fig. 7 shows that there is some fretting with heavy wire indentations at the interface between the outside of the conductor external layer and the internal cylindrical surface of the steel square-faced bushing. These fretting line marks are mainly located at the top and bottom positions of the conductor crosssection; these marks start from the edge of the steel bushing and go up to $22 \mathrm{~mm}$ under the bushing (later, this axial position will determine an effective fixed end - abbreviation $F E$ ). The contour of these heavy wire indentations shows a sharp straight line edge corresponding to the bushing edge and it is at this edge that indentations are deepest. Such indentations appear to be the result of the bushing steel edge crushing the wire of practically pure aluminium, a soft metal compared to harder 


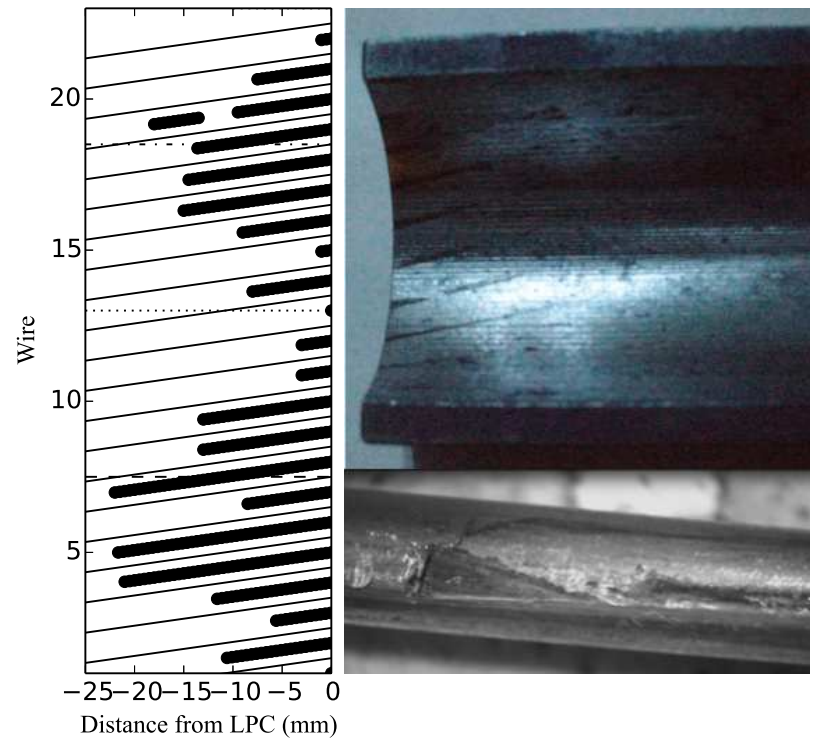

Fig. 7. Photos of fretting marks on the bushing and on a wire of the external layer, along with the mapping of fretting marks between the bushing and the external layer - Bersfort-1

steel edge. In the case of the Drake-1, it was observed that the fretting line marks extend $13 \mathrm{~mm}$ inside the bushing.

Fig. 8 shows that just inside (negative axial position) and just outside of the bushing edge the contact points are predominantly slipping and adherence points compared to what is existing at $50 \mathrm{~mm}$ axial position. Fig. 9 shows that just outside of the bushing all contact points are in slipping or in adherence condition and inside the bushing (not shown in Fig. 9) all contact points are in full adherence.

The localization of the fretting marks seems to indicate that the bending stiffness just at the exit of the square-faced bushing could be large (a significant fraction of $E I_{\max }$ ). Goudreau et al. [23] analysed the Lévesque et al. [10] strain measurements of two typical "short metal-metal suspension clamp-conductor" systems; such systems are quite different from square-faced bushing. The suspension clamp have a curved groove which is supporting the conductor when the latter is bending due to transversal vibration; in fact, the effective LPC moves back and forth on the groove circular arc around the static LPC. With a square-faced bushing, the LPC does not move since the exit is a sharp edge. Goudreau et al. [23] used a "bending taut conductor conforming with the groove shape" model to explain the order of magnitude of the measured strains. In doing so, the conductor bending stiffness was set at $E I_{\max }$ and the contact arc length was adjusted to fit the measured strains.

\section{TWO BENDING STIFFNESS MODEL DEVELOPED TO FIT THE EXPERIMENTAL POINTS}

This model is developed to compute an order of magnitude of the bending rigidity prevailing near the bushing exit (inside and outside). The model uses two distinct values of bending stiffness along the conductor to best fit the experimental data. In [9], a model is describing the mechanical behaviour of a taut

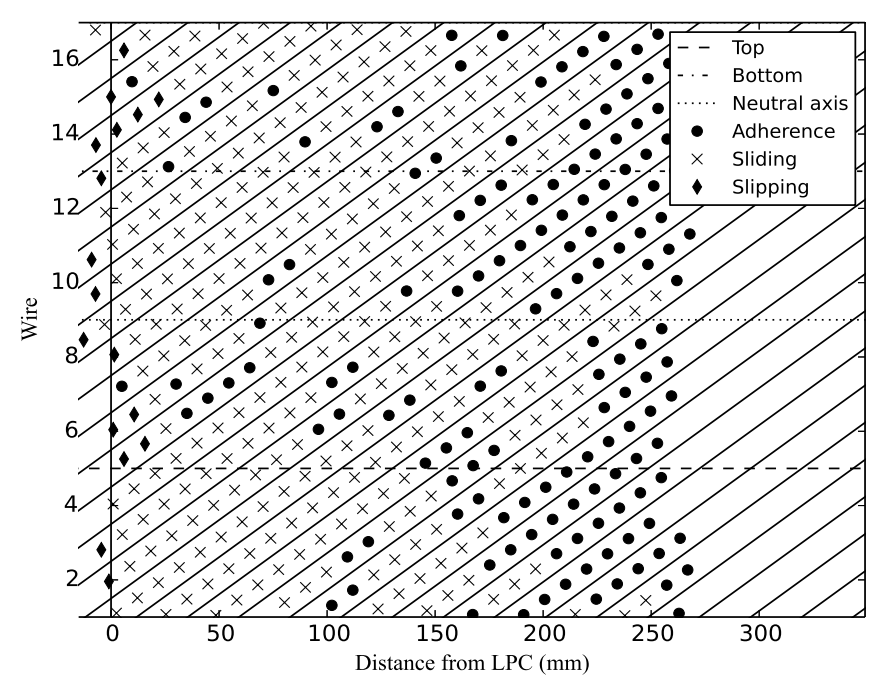

Fig. 8. Contact points of the first layer on the second layer, second layer shown - ACSR Bersfort-1.

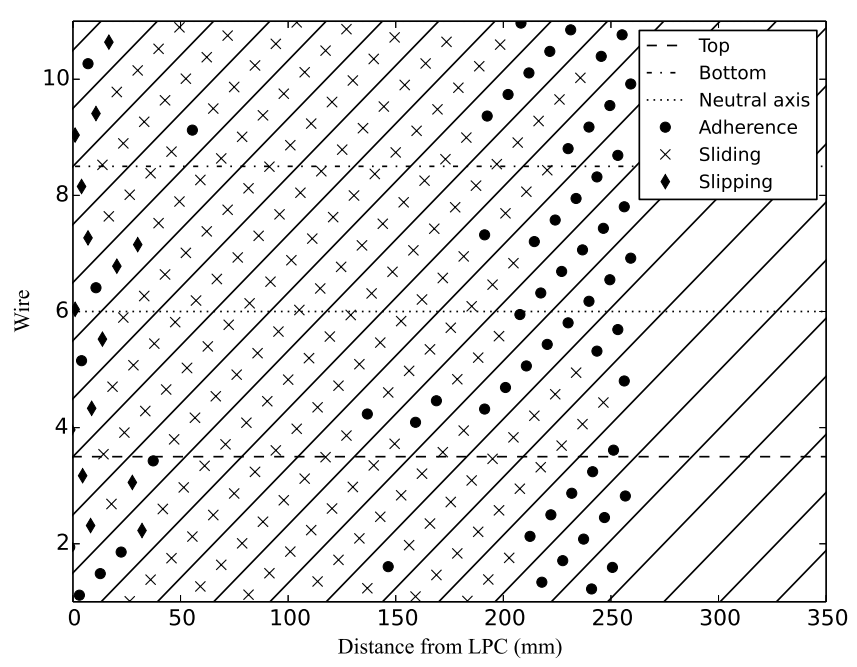

Fig. 9. Contact points of the second layer on the third layer, third layer shown - ACSR Bersfort-1.

conductor under vibration at the exit of a fixed end (squarefaced bushing). Referring to this model, the curvature of the conductor is given by the following differential equation (Fig. $10)$ :

$$
\frac{d^{2} y_{t}}{d x_{t}^{2}}=\frac{M}{E I}=\frac{H}{E I} y_{t}
$$

Since $y_{t}$ approaches 0 for large $x_{t}$ and the traction force $H$ is nearly horizontal at any position (it means that axes $y_{t}$, and $x_{t}$ are assumed to be parallel to respectively $y$ and $x$ ), the complete solution may be written as

$$
y_{1}=A e^{-p_{1} x}+A_{2} x-A_{1} \quad \text { where } \quad p_{1}=\sqrt{\frac{H}{E I_{1}}}
$$

for the conductor extending from the effective fixed end to the horizontal position $x_{1}$. The solution for the second segment of the conductor, extending from $x_{1}$ to $x>(266.7+F E)$, which is the total distance between the effective fixed end and the last measuring point along the span in the experimental 


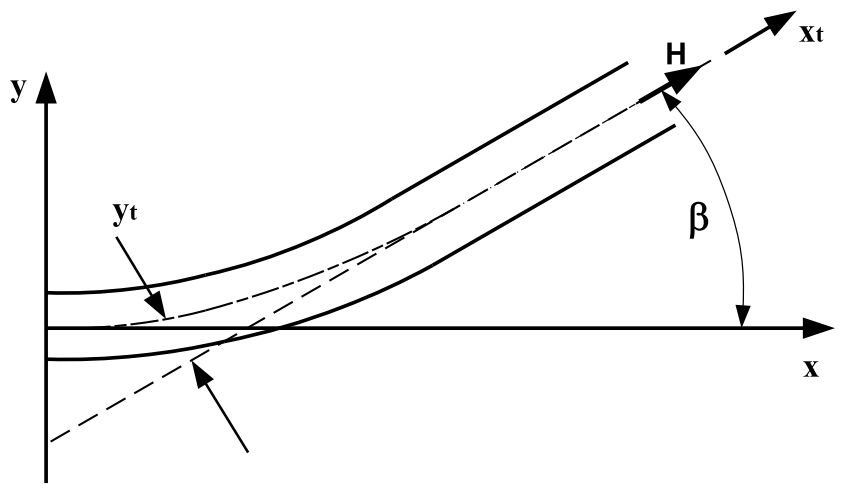

Fig. 10. Bending of a taut conductor.

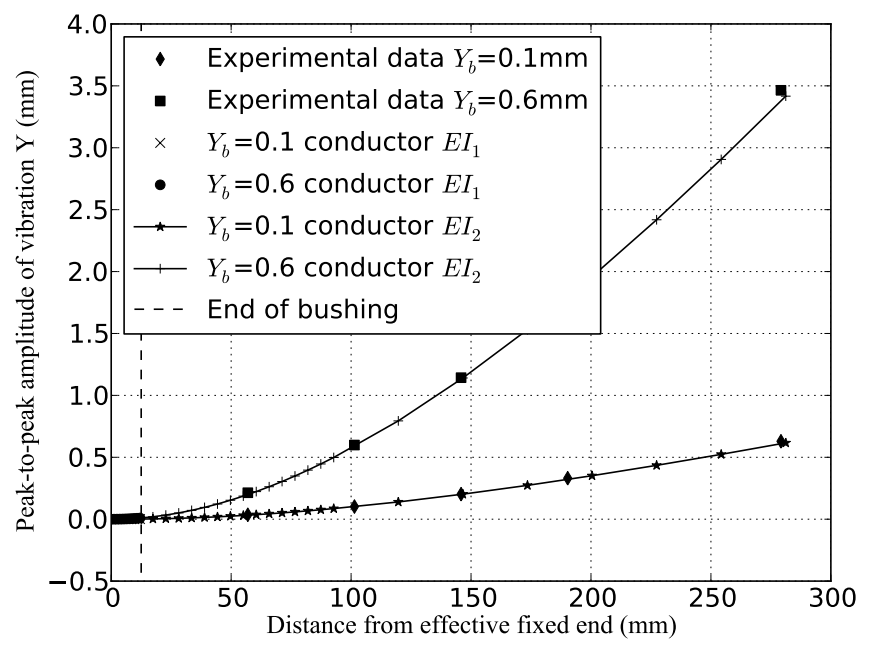

Fig. 11. Deformed shape of the Drake-1 at $H=21 \mathrm{kN}$.

tests, is

$$
y_{2}=C_{3} e^{-p_{2} x}+C_{2} x-C_{1} \quad \text { where } \quad p_{2}=\sqrt{\frac{H}{E I_{2}}}
$$

At $x=0$, the conditions $y_{1}=0$ and $d y_{1} / d x=0$ yield respectively to $A_{2}=p_{1} A$ and $A_{1}=A$. At the position $x_{1}$ where the bending stiffness changes, the geometrical compatibility conditions and the bending moment equilibrium are expressed respectively as follows:

$$
\begin{aligned}
y_{1}\left(x_{1}\right) & =y_{2}\left(x_{1}\right) \\
\frac{d y_{1}\left(x_{1}\right)}{d x} & =\frac{d y_{2}\left(x_{1}\right)}{d x} \\
E I_{1} \frac{d^{2} y_{1}\left(x_{1}\right)}{d x^{2}} & =E I_{2} \frac{d^{2} y_{2}\left(x_{1}\right)}{d x^{2}}
\end{aligned}
$$

There are seven unknowns to solve according to the model developed: $x_{1}, E I_{1}, E I_{2}, A, C_{1}, C_{2}, C_{3}$. Using the three last equations allows to express $C_{1}, C_{2}, C_{3}$ as a function of $A$ and the four unknowns $x_{1}, E I_{1}, E I_{2}, A$ remain to be solved. The experimental data $Y_{45} / 2=y_{2}(44.45 m m+F E)$, $Y_{89} / 2=y_{2}(88.9 m m+F E), Y_{134} / 2=y_{2}(133.35 m m+F E)$, $Y_{178} / 2=y_{2}(177.8 m m+F E), Y_{267} / 2=y_{2}(266.7 m m+F E)$ are used to compute the remaining unknowns in order to get a smooth curve fitting.

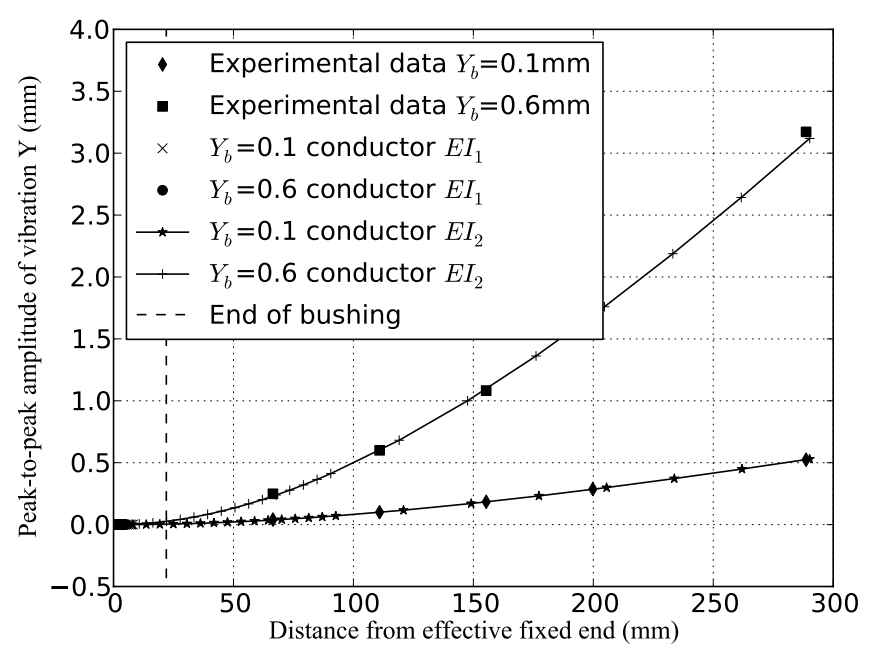

Fig. 12. Deformed shape of the Bersfort- 1 with $H=63 \mathrm{kN}$.

TABLE VIII

CONDUCTOR ACSR DRAKE

\begin{tabular}{|c|c|c|c|c|c|c|c|}
\hline $\begin{array}{c}T \\
(\mathrm{~N})\end{array}$ & $\begin{array}{c}Y_{b} \\
(\mathrm{~mm})\end{array}$ & $\begin{array}{c}F E \\
(\mathrm{~mm})\end{array}$ & $\begin{array}{c}x_{1} \\
(\mathrm{~mm})\end{array}$ & $\frac{E I_{1}}{E I_{\max }}$ & $\frac{E I_{2}}{E I_{\max }}$ & $\begin{array}{c}A \\
(\mathrm{~mm})\end{array}$ & $\begin{array}{c}y_{F E} \\
(\mu \mathrm{m})\end{array}$ \\
\hline 47940 & 0.10 & 13 & 9 & 0.61 & 0.44 & 0.195 & 0.81 \\
\hline 47640 & 0.60 & 13 & 3 & 0.61 & 0.44 & 1.13 & 5.5 \\
\hline 20800 & 0.10 & 13 & 12 & 0.61 & 0.35 & 0.360 & 0.64 \\
\hline 21000 & 0.60 & 13 & 12 & 0.42 & 0.40 & 2.12 & 5.5 \\
\hline
\end{tabular}

Looking at Fig. 11 and 12, we see that it is possible to set the values of the four unknowns (Tables VIII \& IX) such that the resulting curve approximates well the experimental data. Tables VIII \& IX show the parameters calculated and the small vertical displacement $y_{F E}$ at the edge of the bushing (hence at a distance $F E$ from the effective fixed end) for four conditions of tension and bending amplitudes.

Table $\mathrm{X}$ shows the impact of the sliding wires (without friction and axial restriction) on the resulting bending stiffness; it is assumed that only wires of the external layer can slide and the remaining wires are held together "as welded". In summary, this model allows to fit well the experimental data. Looking at Tables VIII, IX \& X, we can observe that bending stiffness tends to be higher very close to the bushing and lower at some distance further from the bushing. This appears to be in agreement with observations of the fretting marks in Fig. 8 and 9.

\section{Conclusion}

Measurements for the deformed shape of two types of ACSR conductors held by square-faced bushings are presented here. The effect of mean tension, vibration mode, and bushing

TABLE IX

CONDUCTOR ACSR BERSFORT

\begin{tabular}{|c|c|c|c|c|c|c|c|}
\hline $\begin{array}{c}T \\
(\mathrm{~N})\end{array}$ & $\begin{array}{c}Y_{b} \\
(\mathrm{~mm})\end{array}$ & $\begin{array}{c}F E \\
(\mathrm{~mm})\end{array}$ & $\begin{array}{c}x_{1} \\
(\mathrm{~mm})\end{array}$ & $\frac{E I_{1}}{E I_{\max }}$ & $\frac{E I_{2}}{E I_{\max }}$ & $\begin{array}{c}A \\
(\mathrm{~mm})\end{array}$ & $\begin{array}{c}y_{F E} \\
(\mu \mathrm{m})\end{array}$ \\
\hline 62690 & 0.10 & 22 & 8 & 0.775 & 0.57 & 0.318 & 1.9 \\
\hline 62530 & 0.60 & 22 & 5 & 0.47 & 0.47 & 1.84 & 13 \\
\hline 27630 & 0.10 & 22 & 8 & 0.61 & 0.44 & 0.630 & 1.9 \\
\hline 27760 & 0.60 & 22 & 8 & 0.44 & 0.35 & 2.81 & 13 \\
\hline
\end{tabular}


TABLE X

BENDING STIFFNESS HYPOTHESIS

\begin{tabular}{|l|c|l|c|}
\hline \multicolumn{2}{|c|}{ Bersfort (22/16/10/6/1) } & \multicolumn{2}{c|}{ Drake (16/10/6/1) } \\
\hline Hypothesis & $\frac{E I}{E I_{\max }}$ & Hypothesis & $\frac{E I}{E I_{\max }}$ \\
\hline $\begin{array}{l}\text { All wires of external } \\
\text { layer are sliding }\end{array}$ & 0.35 & $\begin{array}{l}\text { All wires of external } \\
\text { layer are sliding }\end{array}$ & 0.25 \\
\hline $\begin{array}{l}\text { Wires 1-7 and 1-18 } \\
\text { act as welded (these } \\
\text { wires are assumed to } \\
\text { be in vertical plane) }\end{array}$ & 0.47 & $\begin{array}{l}\text { Top and bottom wires } \\
\text { act as welded (these } \\
\text { wires are assumed to } \\
\text { be in vertical plane) }\end{array}$ & 0.44 \\
\hline $\begin{array}{l}\text { Adding two more } \\
\text { wires (1-6 and } \\
1-17 \text { see Fig. 6) }\end{array}$ & 0.58 & $\begin{array}{l}\text { Adding two mores } \\
\text { wires (two top and } \\
\text { two bottom wires } \\
\text { located symmetrically } \\
\text { referring to the } \\
\text { vertical plane) }\end{array}$ & 0.61 \\
\hline $\begin{array}{l}\text { Adding four more } \\
\text { wires (1-5, 1-8, 1-16, } \\
1-19 \text { see Fig. 6) }\end{array}$ & 0.775 & \\
\hline
\end{tabular}

torque on the deformed shape at various amplitudes were assessed. The variation between specimens was also checked.

This experimental study provides valuable data to compare with a numerical model of a vibrating conductor that includes variable bending stiffness. These tests were performed with square-faced bushings to facilitate the comparison with numerical models. However, a similar experimental program should be undertaken using commercial suspension clamps to study experimentally the bending stiffness of vibrating conductors with boundary conditions representative of transmission line spans.

\section{REFERENCES}

[1] G. Diana, U. Cosmai, A. Laneville, A. Manenti, D. Hearnshaw, and K. O. Papailiou, "Chapter 2: Aeolian vibration," in EPRI Transmission Line Reference Book: Wind-Induced Conductor Motion. EPRI, Palo Alto, CA, 2006. 1012317.

[2] K. O. Papailiou, "On the bending stiffness of transmission line conductors," IEEE transactions on Power Delivery, vol. 12, no. 4, pp. 1576$1588,1997$.

[3] J. Lanteigne, "Theoretical estimation of the response of helically armored cables to tension, torsion, and bending," Transactions of the ASME, Journal of Applied Mechanics, vol. 52, no. 2, pp. 423-32, 1985.

[4] J.-P. H. Paradis and F. Legeron, "Modelling of the free bending behavior of a multilayer cable taking into account the tangential compliance of contact interfaces," in Ninth International Symposium on Cable Dynamics, Shanghai, China, October 18-20, 2011, pp. 95-102.

[5] J.-B. Dastous, "Nonlinear finite-element analysis of stranded conductors with variable bending stiffness using the tangent stiffness method," IEEE Transactions on Power Delivery, vol. 20, no. 1, pp. 328-338, 2005.

[6] S. Langlois, F. Legeron, and F. Levesque, "Time history modeling of vibrations on overhead conductors with variable bending stiffness," IEEE Transactions on Power Delivery, vol. 29, no. 2, pp. 607-614, 2014.

[7] S. Guérard, P. Van Dyke, and J. L. Lilien, "Evaluation of power line cable fatigue parameters based on measurements on a laboratory cable test span," in Eight International Symposium on Cable Dynamics, Paris, France, September 20-23, 2009.

[8] R. Claren and G. Diana, "Dynamic strain distribution on loaded stranded cables," IEEE Transactions on Power Apparatus and Systems, vol. vol PAS-88, no. 11, pp. 1678-1686, 1969.

[9] L. Cloutier, S. Goudreau, and A. Cardou, "Chapter 3: Fatigue of overhead conductors," in EPRI Transmission Line Reference Book: Wind-Induced Conductor Motion. EPRI, Palo Alto, CA, 2006. 1012317.

[10] F. Lévesque, S. Goudreau, A. Cardou, and L. Cloutier, "Strain measurements on ACSR conductors during fatigue tests I - experimental method and data," IEEE Transactions on Power Delivery, vol. 25, no. 4, pp. $2825-2834,2010$

[11] F. Lévesque, S. Goudreau, S. Langlois, and F. Légeron, "Experimental study of dynamic bending stiffness of ACSR Drake overhead conductor," in Ninth International Symposium on Cable Dynamics, Shanghai, China, 2011.
[12] F. Lévesque, "Etude de l'applicabilité de la règle de Palmgren-Miner aux conducteurs électriques sous chargements de flexion cyclique par blocs," Master's thesis, Département de génie mécanique, Université Laval, 2005.

[13] CIGRÉ, "Report on aeolian vibrations," Electra, no. 124, pp. 40-77, 1986.

[14] M. Lutchansky, "Axial stresses in armor wires of bent submarine cables," Journal of Energy Engineering, vol. 91, pp. 687-693, 1969.

[15] R. H. Knapp, "Helical wire stresses in bent cables," Journal of Offshore Mechanics and Arctic Engineering, vol. 110, pp. 55-61, February 1988.

[16] G. Feld, R. I. Reuben, D. G. Owen, and A. E. Crockett, "Power cables and umbilicals - conductor strain under pure bending," in Proceedings of the First International Offshore and Polar Engineering Conference, Edinburgh, United Kingdom, 1991.

[17] A. A. Fadel, D. Rosa, L. B. Mur ${ }_{s}$ ca, J. L. A. Fereira, and J. A. Araújo, International Journal of Fatigue, vol. doi:10.1016/j.ijfatigue.2011.03.007, 2011.

[18] C. B. Rawlins, "Chap. 2: Fatigue of overhead conductors," in Transmission Line Reference Book - Wind-Induced Conductor Motion. EPRI Res. Project 792, Palo Alto, CA, 1979.

[19] S. Goudreau, F. Lévesque, A. Cardou, and L. Cloutier, "Strain measurements on ACSR conductors during fatigue tests II - stress fatigue indicators," IEEE Transactions on Power Delivery, vol. 25, no. 4, pp. 2997-3006, 2010.

[20] F. Lévesque and F. Légeron, "Effect of mean tension on interwire contacts in overhead conductors," in Ninth International Symposium on Cable Dynamics, Shanghai, China, 2011.

[21] CIGRE, "Les vibrations éoliennes des conducteurs des lignes de transport aériennes (aeolian vibration on overhead lines)," Conférence Internationale des Grands Réseaux électriques, Paper 22-11, 1970.

[22] R. B. Waterhouse, "Fretting fatigue," International Materials Reviews, vol. 37, no. 2, pp. 77-97, 1992.

[23] S. Goudreau, F. Lévesque, A. Cardou, and L. Cloutier, "Strain measurements on ACSR conductors during fatigue tests III - strains related to support geometry," IEEE Transactions on Power Delivery, vol. 25, no. 4, pp. 3007-3016, 2010.

Dr. Frédéric Lévesque received the M.Sc., and Ph.D. degrees in mechanical engineering from the Université Laval, Québec City, QC, Canada. He was a postdoctoral Fellow from 2009 to 2011 at the Université de Sherbrooke, QC, Canada. Dr. Lévesque now works as a technical leader for RD Énergie in design and engineering of hydromechanical and heavy mechanical equipments.

Dr. Sylvain Goudreau Sylvain Goudreau received the Master's degrees in mechanical engineering from École Polytechnique de Montréal, QC, Canada in 1980, and the Ph.D. degree in mechanical engineering from Université Laval in 1990. He was a Professor with the Department of Mechanical Engineering, Université Laval and he is retired since September 2014. His research activities were related to fatigue problems of overhead conductors.

Dr. Sébastien Langlois received the M.Ing. in civil engineering from McGill University, Montreal, QC, Canada in 2007 and the Ph.D from the Université de Sherbrooke, in 2013. He is now an assistant professor at the Université de Sherbrooke. His research interests are the structural and mechanical behaviour of transmission line structures and the effect of wind on transmission lines.

Dr. Frédéric Legeron the M.Sc.A. from Université de Sherbrooke in 1994, and the PhD from Université de Sherbrooke and Ecole Nationale des Ponts et Chaussées, Paris, France in 1998. He was a professor at Université de Sherbrooke from 2004 to 2014. Dr. Legeron is now a Bridge and Tunnel district manager at Parsons Corporation in the United Arab Emirates. 